\title{
STOCHASTIC ANALYSIS AND GENERATION OF MONTHLY AND 14-DAY EVAPORATION DATA
}

\author{
A.W.JAYAWARDENA* and W.H.LAU*
}

\begin{abstract}
In this paper, two hydrometeorological series, namely, monthly and 14-day evaporation data measured at the Hong Kong Royal Observatory King's Park meteorological station were decomposed into their respective constituent components. The dependent stochastic components were represented by Box-Jenkins type Auto Regressive Moving Average (ARMA) models while the independent random components were represented by various probability distribution functions. Synthetic data were generated by carrying out the decomposition procedure in the reverse order and compared with recorded data. The basic statistical characters have been satisfactorily preserved.
\end{abstract}

KEY WORDS : Evaporation, Evapotranspiration, Trend and periodicity analysis, ARMA modelling, Synthetic data generation

\section{INTRODUCTION}

Long term records of hydrometeorological data which are necessary for regional water balance as well as for planning of water resources development projects are often unavailable in many areas. In such situations hydrologists often resort to the generation of synthetic data which will have the same statistical characteristics as those of the available data series. The properties of the constituent components obtained by the decomposition of the available data series form the basis for such data generation.

Time series analysis approach of modelling has been used in many branches of engineering. For example, in stochastic hydrology it has been used by Ngan and Russell (1986) to make real-time flow forecasting using Kalman filtering, by Srikanthan and McMahon (1982) to simulate annual and monthly rainfalls with the help of disaggregation models, by Gupta and Chauhan (1986) to model weekly irrigation requirements, by Jayawardena and Lai (1989) to model water quality. However, not much work has been carried out on stochastic evaporation and evapotranspiration analysis.
Over the years, the emphasis in evaporation and evapotranspiration analysis have been mainly on estimation techniques using empirical and semiempirical approaches (For example, Penman, 1948; Thornthwaite, 1948). Such techniques need calibra. tion on a regional basis. Al-Shalan and Salih (1988) used 23 currently available empirical methods to estimate the evapotranspiration in central Saudi Arabia. For Hong Kong, several original empirical equations have been modified and calibrated (Chen, 1976; Ramage, 1959; Jayawardena, 1989). The first one to model the stochastic structure of annual water losses (evaporation and infiltration) was perhaps Chang (1988) who made real time forecasts using the minimum mean square error technique developed by Box and Jenkins (1976). In short term hydrological system operation however, it is more desirable to use monthly or even 14-day data series for simulation and forecasting.

In this study, an attempt is made to describe the stochastic character of the monthly and 14-day evapo. ration data in Hong Kong. The period of records used for analysis is from Jan 1973 to Dec 1982 . The month-

"Dept. of Civil and Structural Eng., University of Hong Kong 
ly values were obtained by summing up the daily pan evaporation values for each month while the 14-day data were obtained by summing up the daily values for each 14-day period. Synthetic data were then generated using the appropriate probability distribution function of the residual series. The basic statistical character of the generated data when compared with that of the observed records for the period Jan 1983 to Dec 1986 was found to be reasonably well preserved.

\section{METHOD OF ANALYSIS}

A time series in general consists of a trend, a periodic component, a dependent stochastic component and an independent random component. The structure of the series is studied by decomposing into these constituent components.

A series may be stationary or non stationary. A non stationary series can sometimes be made stationary by some transformation or by taking differences. Stationarity is a pre-requisite for linear stochastic modelling.

\section{Trend}

A number of tests exists for the detection of a trend; for example, the cumulative deviation test for departure from homogeneity (Buishand, 1982) and Kendall's rank correlation test (Kottegoda, 1980). In these tests, a hypothesis of no trend is initially made and statistical tests are carried out to accept or reject the hypothesis.

In the cumulative deviation test, the departure from homogeneity is tested using the statistic $Q$ which is defined as

$$
\begin{array}{r}
\mathrm{Q}=\max \left|\mathrm{S}_{\mathrm{k}}^{* *}\right| \\
0 \leq \mathrm{k} \leq \mathrm{N}
\end{array}
$$

in which the rescaled adjusted partial sums $S_{k}^{* *}$ are given by

$$
\mathrm{S}_{\mathbf{k}}^{* *}=\mathrm{S}_{\mathbf{k}}^{*} / \sigma_{\mathrm{x}}
$$

where $S_{k}^{*}$,the adjusted partial sums are given by

$$
\begin{aligned}
& \mathrm{S}_{\mathrm{k}}^{*}=\sum_{\mathrm{t}=1}^{\mathrm{k}}\left(\mathrm{x}_{\mathrm{t}}-\overline{\mathrm{x}}\right), \mathrm{k}=1,2, \cdots \cdots \mathrm{N} \\
& \mathrm{S}_{0}^{*}=0
\end{aligned}
$$

In equation (2), $\sigma_{\mathrm{x}}$ is the standard deviation of the series $x_{t}$ of length $N$ and mean $\bar{x}$.
High values of $Q$ indicates departure from homogeneity. Critical values based on 19,999 synthetic Gaussian random numbers have been given by Buishand (1982)

In Kendall's rank correlation test, the number of times, $p$, in all pairs of observations $x_{i}, x_{j}: j>i$ that $x_{j}>x_{1}$ is determined, The test is carried out using the statistic $\tau$ defined as

$$
\tau=\frac{4 \mathrm{p}}{\mathrm{N}(\mathrm{N}-1)}-1
$$

which is then expressed as a standard normal variate in the form:

$$
z=\frac{\tau-\bar{t}}{\sqrt{\operatorname{var}(\bar{\tau})}}
$$

where $\bar{\tau}$ is the expected value of $\tau$ ( $=0$ if the series is normal) and $\operatorname{Var}(\bar{\tau})$ is its variance $\left(=\frac{2(2 \mathrm{~N}+5)}{9 \mathrm{~N}(\mathrm{~N}-1)}\right)$.

The computed $z$ and $Q$ variates are compared with their critical values from tables at a given level of significance. If the calculated value of the variate is within the region of acceptance, the hypothesis of no trend is accepted. If a trend is detected, it can be removed by fitting a regression equation or a polynomial.

\section{Periodicity}

Detection of periodicity can be made by the auto correlation (time-domain) and/or the spectral (frequency-domain) analysis. If the series is periodic, the auto correlogram will also be periodic. In the spectral density function, periodicity will appear as a peak at a frequency corresponding to the periodicity. The discrete auto correlation function assuming stationarity can be written in the form

$$
\mathrm{r}_{\mathrm{k}}=\frac{\frac{1}{\mathrm{~N}-\mathrm{k}}\left(\sum_{\mathrm{t}=1}^{N-k}\left(\mathrm{x}_{\mathrm{t}}-\overline{\mathrm{x}}\right)\left(\mathrm{x}_{\mathrm{t}+\mathrm{k}}-\overline{\mathrm{x}}\right)\right)}{\frac{1}{\mathrm{~N}}\left(\sum_{\mathrm{t}=1}^{N}\left(\mathrm{x}_{\mathrm{t}}-\overline{\mathrm{x}}\right)^{2}\right)}
$$

and the raw spectral density function is given by (Bendat and Piersol, 1971)

$$
G(f)=2 \Delta t\left\{r_{0}+2 \sum_{k=1}^{M-1} r_{k} \cos (2 \pi f k)+r_{M} \cos (2 \pi f M)\right\}
$$

where $\mathbf{r}_{\mathbf{k}}-$ the serial auto correlation coefficient at lag $\mathrm{k}$;

$\overline{\mathbf{x}}-$ the mean of $x_{t}$; $G(f)$ - the raw spectral density function ;

$f-$ the frequency ; $\Delta t$ - the time interval between two obser- 
vations ;

$M$ - the maximum lag considered in the auto correlogram.

If a periodicity exists, it can be represented by a Fourier series. The trend, if any, is assumed to have been removed at this stage. The Fourier series representation takes the form :

$$
\mathrm{m}_{\mathrm{r}}=\mu+\sum_{i=1}^{n}\left(\mathrm{~A}_{1} \cos \left(\frac{2 \pi \mathrm{i} \tau}{\mathrm{p}}\right)+\mathrm{B}_{1} \sin \left(\frac{2 \pi \mathrm{i} \tau}{\mathrm{p}}\right)\right)
$$

where $\mathrm{m}_{\mathrm{r}}$-the harmonically fitted means for each $\tau(\tau=1,2 \ldots \mathrm{p})$;

$\mu$ - the population mean;

$\mathrm{h}-$ the total number of harmonics $(=\mathrm{p} / 2$ or $(p-1) / 2)$ depending upon whether $p$ is even or odd

$\mathrm{p}-$ the period ;

and,

$A_{1}, B_{1}$, obtained by minimizing the $\Sigma\left(m_{\tau}-\bar{x}_{\tau}\right)^{2}$ are

$$
\mathrm{A}_{1}=\frac{2}{\mathrm{p}} \sum_{\tau=1}^{\mathrm{p}} \overline{\mathrm{x}}_{\tau} \cos (2 \pi \mathrm{i} \tau / \mathrm{p}) \quad \mathrm{i}=1,2, \cdots \cdots \mathrm{h} .
$$

$\mathrm{B}_{\mathrm{i}}=\frac{2}{\mathrm{p}} \sum_{\tau=1}^{\mathrm{p}} \overline{\mathrm{x}}_{\tau} \sin (2 \pi \mathrm{i} \tau / \mathrm{p}) \quad \mathrm{i}=1,2, \cdots \cdots \mathrm{h}$.

The observed seasonal means are given by

$$
\overline{\mathrm{x}}_{\tau}=\frac{\mathrm{p}}{\mathrm{N}} \sum_{i=1}^{\mathrm{N} / \mathrm{P}} \mathrm{x}_{\tau+\mathrm{p}(1-1)} \quad \tau=1,2, \cdots \cdots \mathrm{p}
$$

For monthly data $p=12$, and therefore $h=6$. But for most practical purposes, it may not be necessary to expand the Fourier series up to maximum number of harmonics. By examining the cumulative periodogram, which is a plot of the ratio of the explained variance to the total variance as a function of the number of harmonics, it is possible to determine the relative significance of each harmonic and hence obtain the maximum number of significant harmonics, $h^{*}$ (Salas et al, 1980). It will show a rapidly rising part up to $\mathrm{h}^{*}$ and a slowly increasing part thereafter up to its maximum value of unity at $h$. The ratio of variances, $P_{\mathrm{l}}$, is defined as

$$
P_{j}=\frac{\sum_{i=1}^{1}\left(A_{1}^{2}+B_{1}^{2}\right) / 2}{\frac{1}{p} \sum_{r=1}^{p}\left(\bar{x}_{r}-p\right)^{2}} \quad j=1,2, \cdots \cdots \cdot h
$$

where $\hat{\mu}$, the estimate of $\mu$ is the mean of $\overline{\mathbf{x}}_{r}$. In plotting the periodogram, the explained variance which is given by the numerator of equation (12) is assumed to be arranged in decreasing order of magnitude from $i=1$ to $i=j$.

\section{Stochastic component}

The stochastic component of the series, $Z_{t}$ is obtained by subtracting the periodic component defined by the Fourier series (which contains the mean) from the trend free series, and subsequently dividing by the periodic standard deviations. Periodic standard deviations are estimated by Fourier fitting in the same way as the periodic means. The stochastic component in general contains a dependent part which may be represented by an ARMA(p,q) model (Box and Jenkins, 1976) where $p$ and $q$ are the orders of the Auto Regressive and Moving Average models respectively, and an independent part which can only be described by a probability distribution function.

The general ARMA(p,q) model is given by

$$
\phi_{\mathrm{p}}(\mathrm{B}) \mathrm{z}_{\mathrm{t}}=\theta_{\mathrm{q}}(\mathrm{B}) \eta_{\mathrm{t}}
$$

where $\eta_{t}$ is the independent part ; $\phi$ and $\theta$ are the AR and MA coefficients and $B$ is a back shift operator in time $\left(\mathrm{B}^{\mathrm{p}} \mathrm{z}_{\mathrm{t}}=\mathrm{z}_{\mathrm{t}-\mathrm{p}}\right)$.

Synthetic data can be generated by following the above procedure in exact reverse order starting from a sample of the independent residual series generated from its probability density fumction.

\section{DATA ANALYSIS AND RESULTS}

\section{Stationarity and trend}

In testing the stationarity, each series was divided into three approximately equal sub series and their means and standard deviations computed. The statistic ' $t$ ' defined in equation (14), and which follows the Student's ' $t$ ' distribution was used in the test.

$$
\mathrm{t}=\frac{\overline{\mathrm{x}}-\mu}{\sigma} \sqrt{\mathrm{N}-1}
$$

where $\bar{x}$ - the mean of the sub series,

$\mu-$ the mean of whole series, and,

$\sigma-$ the standard deviation of the sub series.

Tables-1 and. 2 show the summary of the statistics and the results of trend and stationarity tests of the two series. For the detection of possible trends, the cumulative deviation test and Kendall rank correlation test show that the hypothesis of no trend cannot be rejected at $5 \%$ level of significance for both series. The values of the statistic ' $t$ ' for each sub series were found to lie wihtin the critical limits at the $5 \%$ level of significance. Therefore both series are assumed to be stationary. 
Table-1(a) Statistics of stationarity tests for the monthly series at $5 \%$ level of significance

\begin{tabular}{|l|l|l|l|l|}
\hline statistic & $\begin{array}{l}\text { whole series } \\
\mathrm{mm}\end{array}$ & $\begin{array}{l}\text { first } \\
\text { one third } \\
\mathrm{mm}\end{array}$ & $\begin{array}{l}\text { second } \\
\text { one-third } \\
\mathrm{mm}\end{array}$ & $\begin{array}{l}\text { last } \\
\text { one-third } \\
\mathrm{mm}\end{array}$ \\
\hline mean & 127.9 & 126.5 & 131.4 & 125.7 \\
\hline $\begin{array}{l}\text { standard } \\
\text { deviation }\end{array}$ & 33.70 & 31.93 & 37.32 & 32.13 \\
\hline $\begin{array}{l}\text { Statistic } \\
\text { 't } \\
\text { critical } \\
\text { values }\end{array}$ & & -0.2738 & 0.5857 & -0.4276 \\
\hline
\end{tabular}

Table-1(b) Statistics of the stationarity tests for the 14-day series at $5 \%$ level of significance

\begin{tabular}{|l|l|l|l|l|}
\hline statistic & $\begin{array}{l}\text { whole series } \\
\mathrm{mm}\end{array}$ & $\begin{array}{l}\text { first } \\
\text { one third } \\
\mathrm{mm}\end{array}$ & $\begin{array}{l}\text { second } \\
\text { one-third } \\
\mathrm{mm}\end{array}$ & $\begin{array}{l}\text { last } \\
\text { one-third } \\
\mathrm{mm}\end{array}$ \\
\hline mean & 58.83 & 58.21 & 60.44 & 57.88 \\
\hline $\begin{array}{l}\text { standard } \\
\text { deviation }\end{array}$ & 16.97 & 15.53 & 18.76 & 16.65 \\
\hline $\begin{array}{l}\text { Statistic } \\
\text { t' } \\
\begin{array}{l}\text { critical } \\
\text { values }\end{array}\end{array}$ & -0.3680 & 0.7912 & -0.5322 \\
\pm 1.9917 & \pm 1.9917 & \pm 1.9910 \\
\hline
\end{tabular}

Table -2 Statistics of the trend tests at $5 \%$ significance level

\begin{tabular}{|l|l|l|l|}
\hline Test & statistic & monthly series & 14 -day series \\
\hline $\begin{array}{l}\text { Cumulative } \\
\text { deviation }\end{array}$ & Q $/ \sqrt{\mathrm{N}}$ & 0.676 & 0.933 \\
& critical values & 1.36 & 1.36 \\
\hline Kendall's & Kendall's 'z' & -0.4174 & -0.7449 \\
rank corre & critical values & \pm 1.96 & \pm 1.96 \\
lation & ration & \\
\hline
\end{tabular}




\section{Periodicity}

The auto correlogram and the spectral density functions (the latter is shown in Fig.1) clearly show the periodic character of the 2 sets of data. Tables 3 and 4 summarize the results of the harmonic analysis for the two series. For the means of both series the first harmonic explains more than $90 \%$ of the variance and 4 harmonics are sufficient to explain over $96 \%$ of the variance.

For the monthly series, the significant harmonics for the mean are the 1st, 2nd, and 5th while those for the standard deviation are 1st, 5th and 3rd. They together explain approximately $99 \%$ and $96 \%$ respectively of the variance. However, in this case, all six harmonics were retained since the extra number of parameters needed are not too many. For the 14-day series, the significant harmonics are the 1st, 2nd, 5th and 12th for the mean while those for the standard deviation are 1st, 3rd, 7th, 5th, 11th, 9th, 4th, and 8th. The significant harmonics for the mean and the standard devia. tion are determined independently, and therefore can be different. These harmonics together explain approximately $96 \%$ of the variance.

With the necessary harmonics chosen, each series was then standardized using the Fourier fitted means and standard deviations.

\section{Stochastic component}

Several ARMA models ranging from ARMA $(1,0)$ to ARMA $(2,2)$ were used to describe the dependent structure of the standardized stochastic component. Two criteria based on the properties of the residual series were then used to choose the best ARMA model. The first criterion, the Porte Manteau lack of fit test, is a test of independence of the residuals and uses the statistic $Q_{p}$ defined as

$$
Q_{p}=N \sum_{k=1}^{M} r_{k}^{2}(\eta)
$$

where $r_{k}(\eta)$ is the auto correlation coefficient of the residual series at lag $k$ and $M$ is the maximum lag considered (about $\mathrm{N} / 5$ ). If $m$ is independent, then $Q_{\mathcal{D}}$, which is approximately Chi-squared distributed with M-p-q degrees of freedom, should be less than $\chi^{2}(M-$ p-q). The second criterion known as the Akaike Infor- mation Criterion, AIC, (Akaike, 1974) is a test for parsimony and uses the $\operatorname{AIC}(p, q)$ defined as

$$
\operatorname{AIC}(\mathrm{p}, \mathrm{q})=\mathrm{N} \ln \left(\sigma_{\eta}^{2}\right)+2(\mathrm{p}+\mathrm{q})
$$

where $\sigma_{\eta}^{2}$ is the maximum likelihood estimate of the residual variance. The most parsimonious model is the one which gives the minimum AIC value. For all the models of the two series the statistic $Q_{p}$ is less than $x^{2}(M-p-q)$ at $5 \%$ level of significance (Tables 5 and 6) implying the independence of the residuals. Based on the AIC values, $\operatorname{ARMA}(2,2)$ and $\operatorname{ARMA}(1,1)$ respectively were found to be the optimal models for the monthly and 14-day series.

\section{Residual series}

If the residual series is normally distributed the subsequent analysis and synthesis becomes relatively simpler. Therefore, a test of normality is first carried out. Snedecor and Cochran(1967) suggested a method using the skewness coefficient based on the condition that if the series is normal, the skewness coefficient is asymptotically normal with zero mean and variance $6 / \mathrm{N}$. For large values of $\mathrm{N}$ the hypothesis of normal ity can be accepted at $5 \%$ level of significance if the skewness coefficient lies within the interval \pm 1.96 $\sqrt{6 / \mathrm{N}}$ which for monthly series is the interval \pm 0 . 4383 , and for 14-day series is the interval \pm 0.2977 . From Tables 5 and 6 , it is seen that normality can be accepted for the monthly series but not for the 14-day series.

Table 7 shows the parameters of the three distributions attempted, namely, Normal, Gamma and Log. normal, and their goodness of fit as measured by the statistic $\bar{x}^{2}$ which is defined as

$$
\bar{\chi}^{2}=\sum_{i=1}^{k} \frac{\left(O_{1}-E_{1}\right)^{2}}{E_{1}}
$$

where $\mathbf{k}$ is the number of classes in the sample, $\mathrm{O}_{1}$ is the observed frequency of the class $i$, and $E_{1}$ is the expected frequency of a proposed distribution under the null hypothesis that the observed data is a sample of the proposed probability distribution. In Table 7, A and $B$ are the skewness and scale parameters of the two parameter Gamma distribution, and $\mu$ and $\sigma$ are the mean and standard deviation of the two parameter Log-normal distribution. The $x^{2}$ goodness of fit test is carried out by comparing the statistic $\hat{\boldsymbol{x}}^{2}$ with the critical values of the $\chi^{2}$-distribution with $k-1-a_{1}$ 
研究ノー上 61

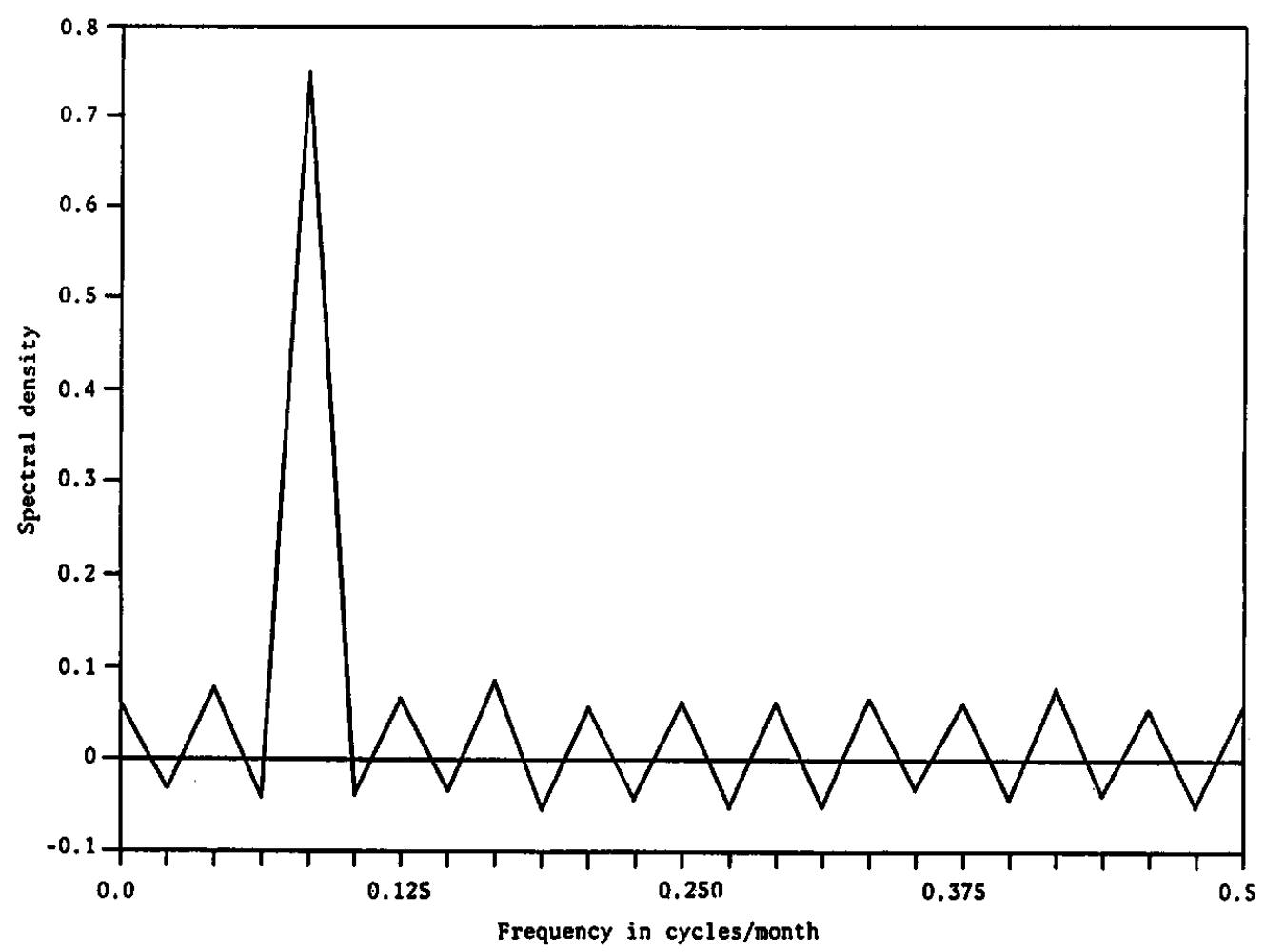

Fig. 1(a) Raw spectrum for monthly data

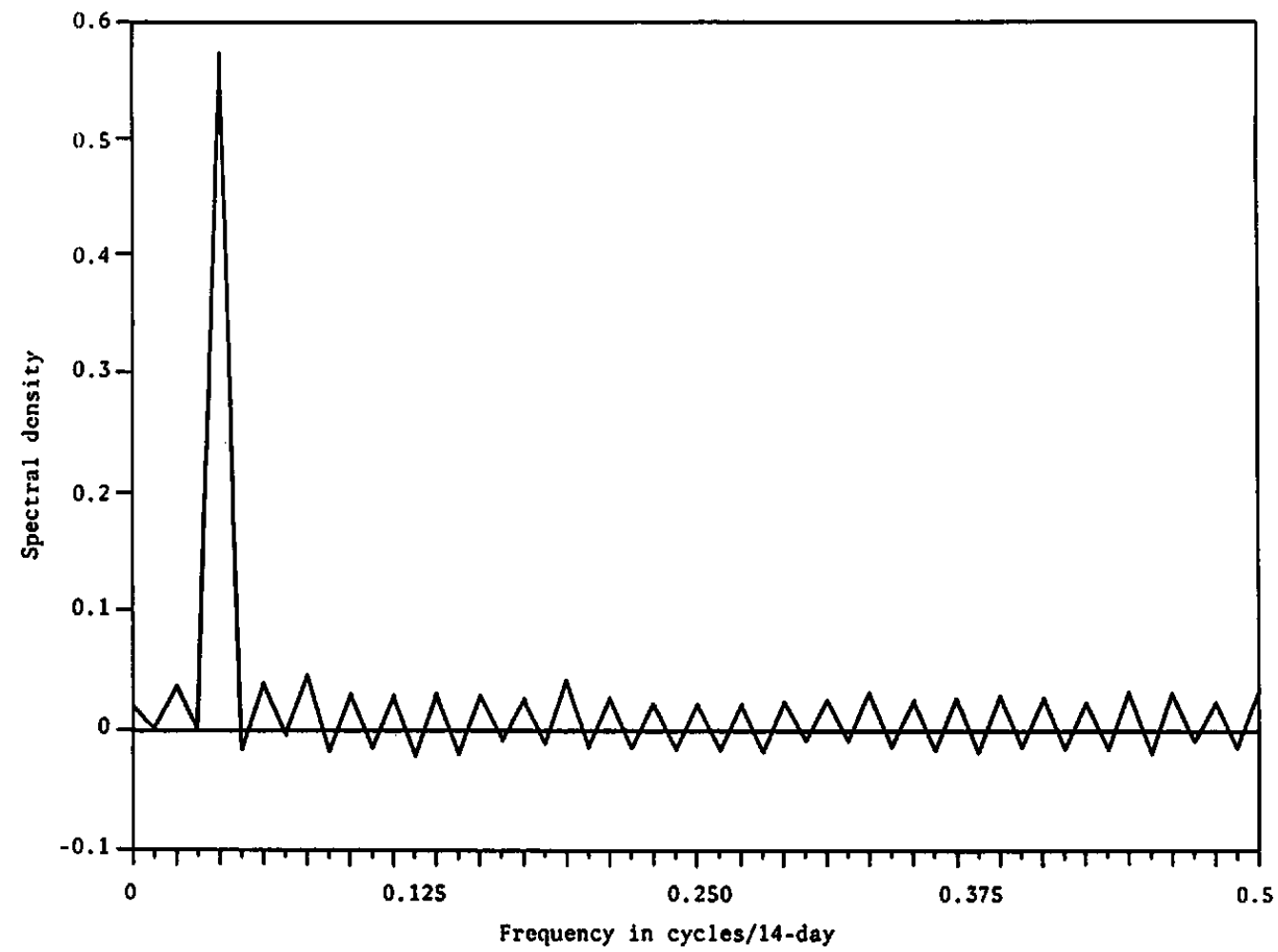

Fig. 1(b) Raw skectrum for 14-day data 
Table-3 Harmonic analysis of monthly data

\begin{tabular}{|c|c|c|c|c|c|c|c|}
\hline \multicolumn{3}{|c|}{ means } & \multicolumn{4}{c|}{ standard deviations } \\
\hline $\begin{array}{c}\text { order of } \\
\text { harmonic }\end{array}$ & $A_{i}$ & $B_{i}$ & $P_{j}$ & $\begin{array}{c}\text { order of } \\
\text { harmonic }\end{array}$ & $A_{i}$ & $B_{i}$ & $P_{j}$ \\
\hline 1 & -19.60 & -33.30 & 0.94 & 1 & -6.82 & -10.80 & 0.86 \\
\hline 2 & 6.52 & -1.45 & 0.97 & 5 & 2.45 & 1.99 & 0.91 \\
\hline 5 & 4.63 & 2.62 & 0.99 & 3 & 0.37 & -2.95 & 0.96 \\
\hline 4 & -1.45 & 3.60 & 1.00 & 2 & 1.72 & -0.45 & 0.97 \\
\hline 3 & 0.56 & -2.56 & 1.00 & 4 & -0.19 & 1.76 & 0.99 \\
\hline 6 & -0.41 & 0.00 & 1.00 & 6 & -1.01 & 0.00 & 1.00 \\
\hline
\end{tabular}

Table-4 Harmonic analysis of 14-day data

\begin{tabular}{|c|c|c|c|c|c|c|c|}
\hline \multicolumn{4}{|l|}{ means } & \multicolumn{4}{|c|}{ standard deviations } \\
\hline $\begin{array}{l}\text { order of } \\
\text { harmonic }\end{array}$ & $A_{i}$ & $B_{i}$ & $P_{j}$ & $\begin{array}{l}\text { order of } \\
\text { harmonic }\end{array}$ & $A_{1}$ & $B_{1}$ & $P_{j}$ \\
\hline 1 & -9.71 & -14.50 & 0.92 & 1 & -3.62 & -3.94 & 0.77 \\
\hline 2 & 2.36 & -0.47 & 0.93 & 3 & -0.23 & -1.55 & 0.84 \\
\hline 5 & 1.07 & -2.12 & 0.95 & 7 & 0.49 & -0.97 & 0.87 \\
\hline 12 & 2.20 & -0.19 & 0.96 & 5 & 0.83 & -0.48 & 0.89 \\
\hline 10 & 1.07 & 1.34 & 0.97 & 11 & 0.65 & 0.57 & 0.91 \\
\hline 13 & -1.13 & 0.00 & 0.98 & 9 & -0.59 & 0.44 & 0.93 \\
\hline 7 & 0.45 & -0.98 & 0.98 & 4 & 0.20 & 0.70 & 0.94 \\
\hline 8 & 0.01 & 1.06 & 0.98 & 8 & 0.28 & 0.66 & 0.96 \\
\hline 9 & -0.99 & 0.13 & 0.99 & 13 & -0.60 & 0.00 & 0.97 \\
\hline 11 & 0.95 & 0.06 & 0.99 & 10 & 0.59 & -0.08 & 0.98 \\
\hline 4 & 0.25 & 0.90 & 0.99 & 12 & 0.46 & -0.03 & 0.98 \\
\hline 6 & 0.73 & 0.49 & 0.99 & 6 & -0.26 & 0.35 & 0.99 \\
\hline 3 & 0.08 & -0.85 & 1.00 & 2 & 0.38 & -0.05 & 0.99 \\
\hline
\end{tabular}


Table -5 Statistics of the residues and the parameters of the models for the monthly series

\begin{tabular}{|c|c|c|c|c|c|c|}
\hline model & $\begin{array}{l}\text { AR } \\
\text { coeff. }\end{array}$ & $\begin{array}{l}\text { MA } \\
\text { coeff. }\end{array}$ & $\begin{array}{l}\text { skewness } \\
\text { coeff. }\end{array}$ & $\overline{A I C}$ & $\begin{array}{c}\text { stat istic } \\
Q_{p}\end{array}$ & $\stackrel{(M}{M}-\dot{p}-95)_{q}^{2}$ \\
\hline $\operatorname{ARMA}(1,0)$ & 0.2116 & & 0.2340 & -5.05 & 23.1 & 33.9 \\
\hline $\operatorname{ARMA}(2,0)$ & $\begin{array}{l}0.1767 \\
0.1740 \\
\end{array}$ & & 0.3380 & -6.78 & 18.4 & 32.7 \\
\hline $\operatorname{ARMA}(0,1)$ & & -0.1589 & 0.2205 & -3.60 & 23.4 & 33.9 \\
\hline $\operatorname{ARMA}(1,1)$ & 0.5764 & 0.3625 & 0.3035 & -4.83 & 21.0 & 32.7 \\
\hline $\operatorname{ARMA}(2,1)$ & $\begin{array}{l}0.3517 \\
0.1334 \\
\end{array}$ & 0.1743 & 0.3524 & -4.93 & 18.4 & 31.4 \\
\hline $\operatorname{ARMA}(0,2)$ & & $\begin{array}{l}-0.1402 \\
-0.2584\end{array}$ & 0.3100 & -7.61 & 17.2 & 32.7 \\
\hline $\operatorname{ARMA}(1,2)$ & 0.3553 & $\begin{array}{r}0.1879 \\
-0.1989\end{array}$ & 0.3484 & -6.47 & 17.1 & 31.4 \\
\hline $\operatorname{ARMA}(2,2)$ & $\begin{array}{r}1.2005 \\
-0.7742 \\
\end{array}$ & $\begin{array}{r}1.0761 \\
-0.7914 \\
\end{array}$ & 0.1865 & -8.40 & 16.8 & 30.1 \\
\hline
\end{tabular}

Table-6 Statistics of the residues and the parameters of the models for the 14-day series

\begin{tabular}{|c|c|c|c|c|c|c|}
\hline model & $\begin{array}{l}\text { AR } \\
\text { coeff. }\end{array}$ & $\begin{array}{l}\text { MA } \\
\text { coeff. }\end{array}$ & $\begin{array}{l}\text { skewness } \\
\text { coeff. }\end{array}$ & $\overline{A I C}$ & \begin{tabular}{|c|} 
statistic \\
$Q_{p}$
\end{tabular} & $\left(\begin{array}{l}\chi_{0}^{2} \\
\left(M_{p}^{\prime}-\frac{9}{q}\right)\end{array}\right.$ \\
\hline $\operatorname{ARMA}(1,0)$ & 0.1860 & & 0.3566 & -8.41 & 40.5 & 67.5 \\
\hline $\operatorname{ARMA}(2,0)$ & $\begin{array}{l}0.1585 \\
0.1384\end{array}$ & & 0.3969 & -12.4 & 32.3 & 66.3 \\
\hline $\operatorname{ARMA}(0,1)$ & & -0.1458 & 0.3392 & -6.24 & 43.6 & 67.5 \\
\hline $\operatorname{ARMA}(1,1)$ & 0.7410 & 0.5723 & 0.4368 & -12.8 & 32.8 & 66.3 \\
\hline $\operatorname{ARMA}(2,1)$ & $\begin{array}{l}0.5747 \\
0.0677 \\
\end{array}$ & 0.4236 & 0.4379 & -11.1 & 31.7 & 65.2 \\
\hline $\operatorname{ARMA}(0,2)$ & & $\begin{array}{l}-0.1450 \\
-0.1303\end{array}$ & 0.3601 & -10.3 & 34.5 & 66.3 \\
\hline $\operatorname{ARMA}(1,2)$ & 0.6455 & $\begin{array}{r}0.4998 \\
-0.0614\end{array}$ & 0.4381 & -11.1 & 31.7 & 65.2 \\
\hline $\operatorname{ARMA}(2,2)$ & $\begin{array}{r}1.5699 \\
-0.7719\end{array}$ & $\begin{array}{r}1.4765 \\
-0.7491\end{array}$ & 0.5312 & -8.18 & 33.0 & 64.0 \\
\hline
\end{tabular}

Table -7 Parameters of the residue series probability distributions

\begin{tabular}{|c|c|c|c|c|c|c|c|c|}
\hline \multirow[t]{2}{*}{ series } & \multirow[t]{2}{*}{ A } & \multirow[t]{2}{*}{ B } & \multirow[t]{2}{*}{$\boldsymbol{\mu}$} & \multirow[t]{2}{*}{$\sigma$} & \multicolumn{3}{|c|}{$x^{2}$} & $x_{0.95}^{2}$ \\
\hline & & & & & Normal & Gamma & $\begin{array}{l}\text { Log- } \\
\text { normal }\end{array}$ & \\
\hline monthly & 118.9 & 0.0917 & 0.866 & 1.466 & 55 & 22 & 130 & 1264 \\
\hline 14-day & 22.2 & 0.2167 & 0.844 & 1.472 & 216 & 19 & 279 & \\
\hline
\end{tabular}


Table -8 Statistical properties of historical and generated series for the monthly data

\begin{tabular}{|l|l|l|l|l|}
\hline series & $\begin{array}{l}\left(10^{3}\right) \\
\text { mean }\end{array}$ & $\begin{array}{l}\left(10^{4)}\right. \\
\text { variance }\end{array}$ & skewness & kurtosis \\
\hline historical & 0.1070 & 0.1235 & 0.0567 & 2.260 \\
\hline $\begin{array}{l}\text { generated } \\
\text { (Normal) }\end{array}$ & 0.1258 & 0.07516 & 0.0710 & 2.154 \\
\hline $\begin{array}{l}\text { generated } \\
\text { (Gamma) }\end{array}$ & 0.1296 & 0.1491 & 0.1211 & 1.858 \\
\hline $\begin{array}{c}\text { generated } \\
\text { (Lognormal) }\end{array}$ & 0.1228 & 0.07391 & -0.1138 & 1.727 \\
\hline
\end{tabular}

Table-9 Statistical properties of historical and generated series for the 14-day data

\begin{tabular}{|l|l|l|l|l|}
\hline series & $\begin{array}{l}\left(10^{2}\right) \\
\text { mean }\end{array}$ & $\begin{array}{c}\left(10^{3}\right) \\
\text { variance }\end{array}$ & skewness & kurtosis \\
\hline historical & 0.4931 & 0.2957 & 0.1732 & 2.526 \\
\hline $\begin{array}{l}\text { generated } \\
\text { (Normal) }\end{array}$ & 0.5845 & 0.2306 & 0.1759 & 2.618 \\
\hline $\begin{array}{l}\text { generated } \\
\text { (Gamma) }\end{array}$ & 0.5975 & 0.2779 & 0.1844 & 2.596 \\
\hline $\begin{array}{c}\text { generated } \\
\text { (Lognormal) }\end{array}$ & 0.5820 & 0.2105 & 0.7373 & 3.843 \\
\hline
\end{tabular}

degrees of freedom at $5 \%$ significance level. For two parameter distributions, $a_{1}=2$, and therefore, the degrees of freedom is $k-3$. A maximum of 100 equal probability intervals were used in equation (17). Before comparison, the variates of the theoretical distributions under the null hypothesis and those of the residual series were standardized. From table 7, it is found that Normal and Gamma distributions pass the test for monthly data while only Gamma distribution passes the test for the 14-day data. The results conform with those of the skewness tests done before.

\section{Synthetic data generation}

Synthetic data were generated for both series starting from samples of the chosen probability density functions. In order to be able to compare with the residual series, these samples must be standardized and transformed to series with mean and standard deviation equal to those of the residual series. The
ARMA model, periodicity and trend (if present) are then added to obtain the complete series. The statistical properties of the series so obtained together with those of the historical series from 1983 to 1986 are given in Tables 8 and 9. For completeness all 3 distributions were used. The data used for comparison have not been used in the calibration part.

For both sets data, it is seen that the series generated using Gamma deviates preserve the basic statistical properties such as mean and variance best. However, skewness is difficult to be preserved. Log-normal generated 14-day series produced a high kurtosis implying that it is more suitable for distributions with extreme values.

Figs. 2(a) and 2(b) show the generated and the historical data series from 1983 to 1986 when using Gamma distribution as the residual generator while Figs. 3(a) 


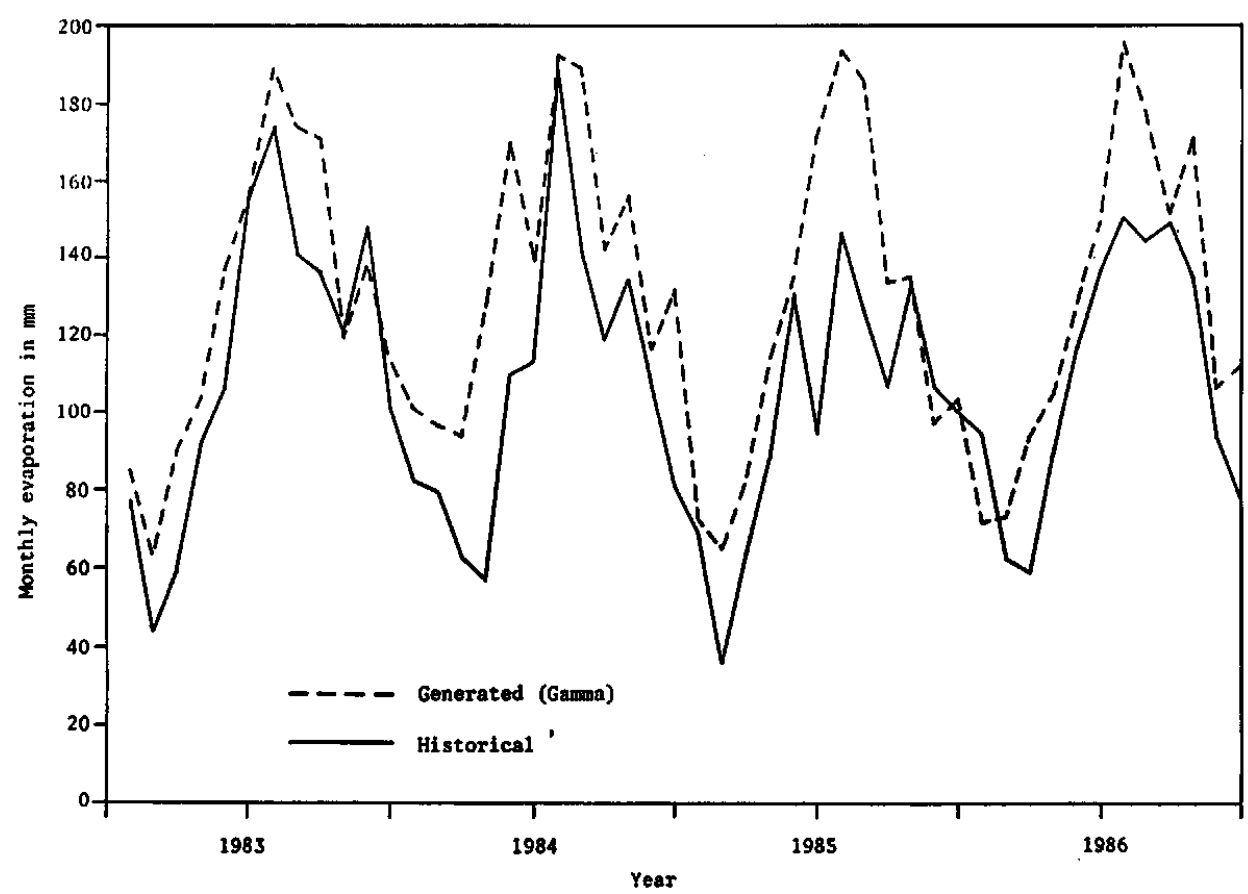

Fig. 2(a) Historical and Gamma generated monthly evaporations

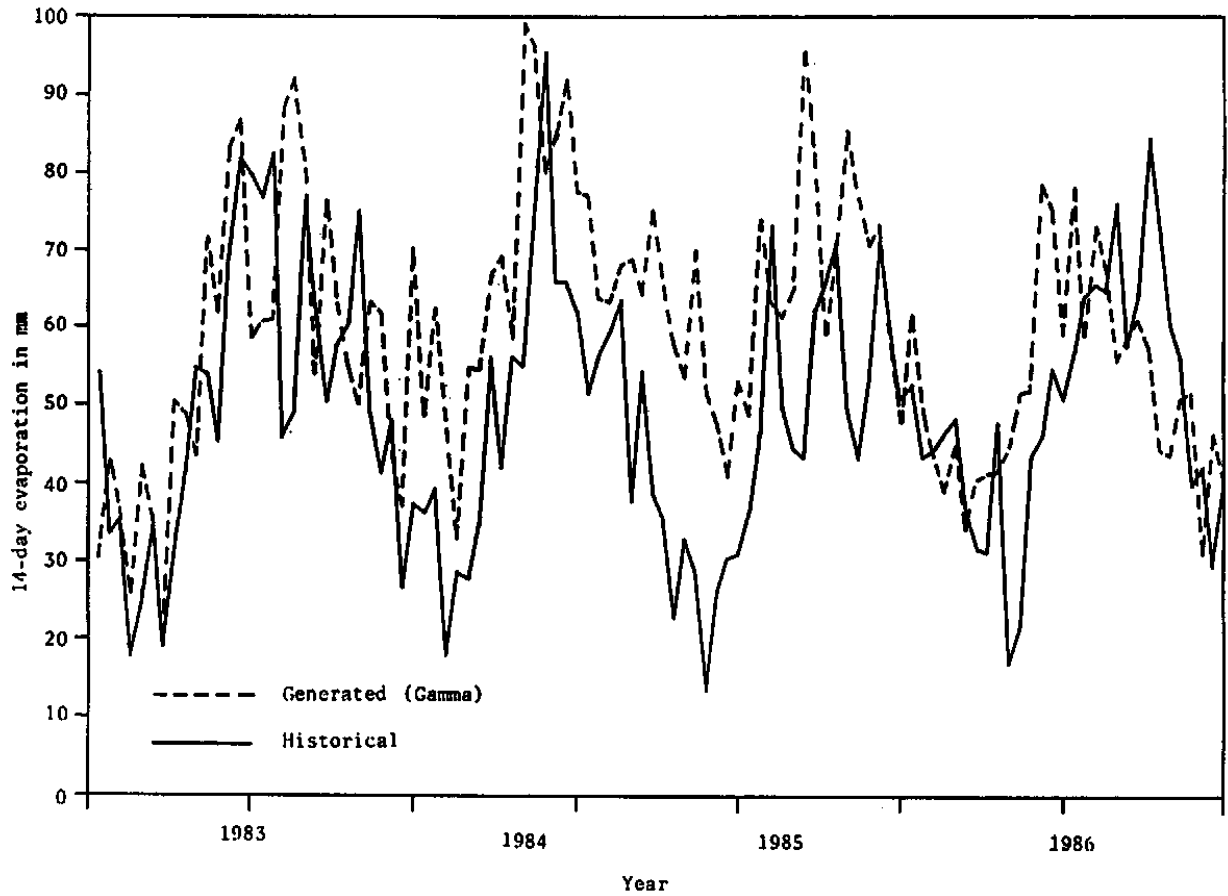

Fig. 2(b) Historical and Gamma generated 14-day evaporations 


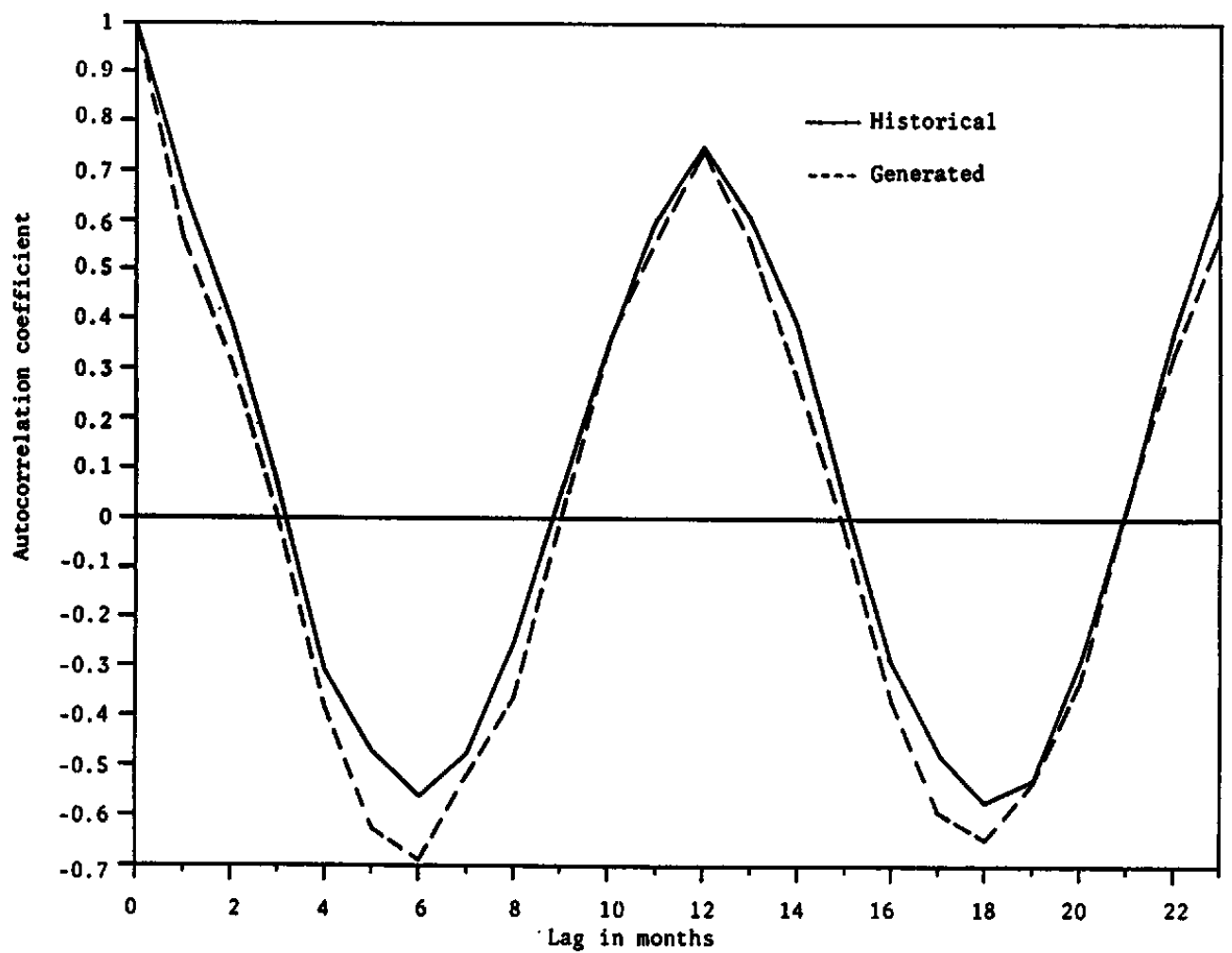

Fig. 3(a) Historical and Gamma generated autocorrelation functions for monthly data

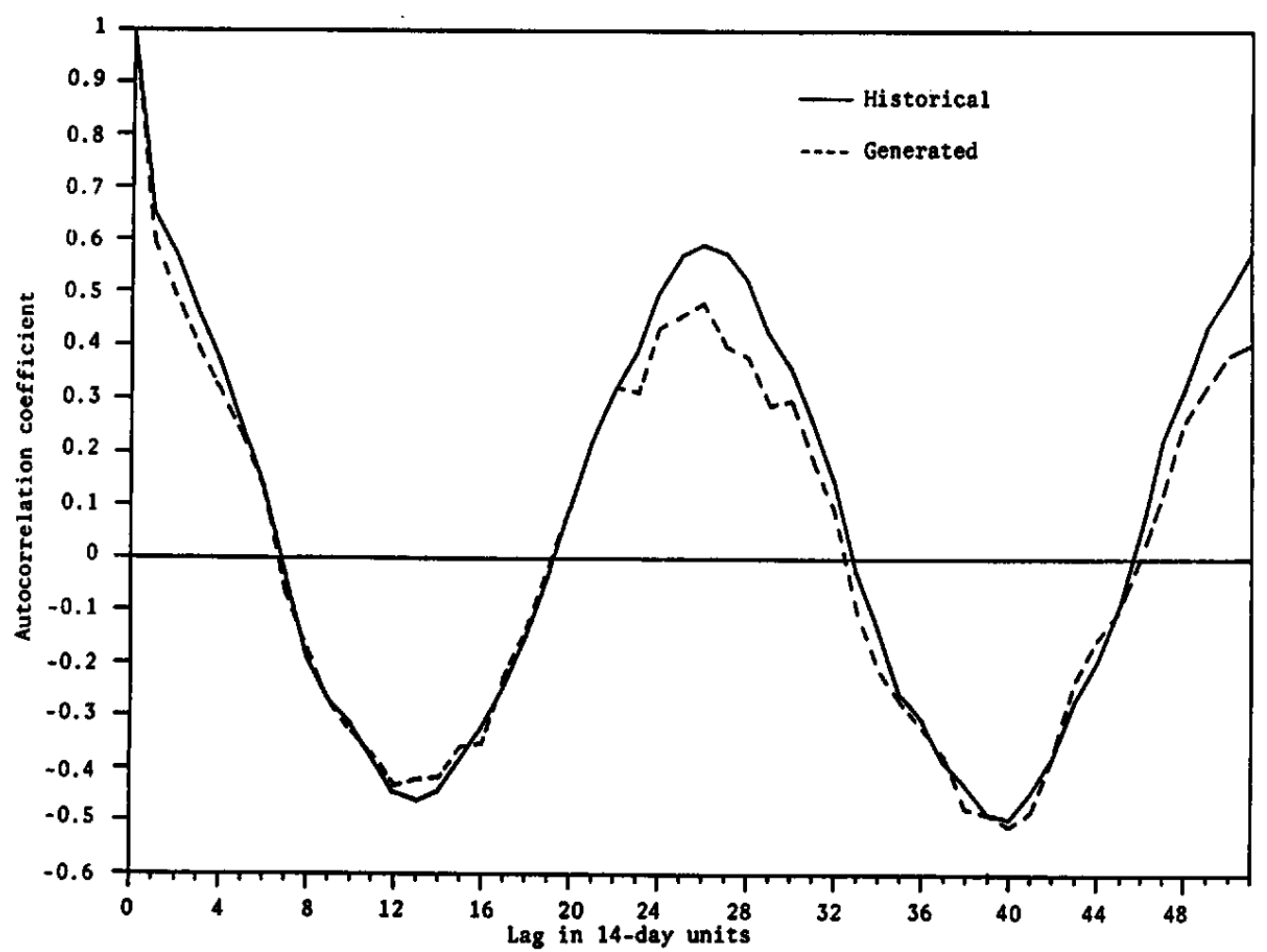

Fig. 3(b) Historical and Gamma generated autocorrelation functions for 14-day data 
and 3(b) show their corresponding auto correlograms.

\section{CONCLUSION}

In this study, the stochastic structure of monthly and 14-day evaporation data at the Hong Kong Royal Observatory King's Park meteorological station has been modelled. The deterministic structure shows no significant trend, but exhibits the expected annual periodicity. The independent residual parts of the monthly series can be taken as Normal, but the Gamma generated synthetic series when compared with historical series gives better statistical agreement. The skewed 14-day residual series is best described by a Gamma distribution.

\section{REFERENCES}

Al-Shalan, S.A. and Salih,A.M.A. (1987): "Evapotranspiration estimates in extremely arid areas", Journal of Irrigation and Drainage Engineering, ASCE, 113(4), 565-574.

Akaike, H. (1974): "A new look at the statistical model identification",IEEE Trans. on Automatic Control, AS-19, 6, 716-723.

Bendat, J.S. and Piersol, A.G. (1971): Random data : Analysis and measurement procedures, John Wiley, New York.

Box, G.E.P. and Jenkins, G.M. (1976): Time series analysis : Forecasting and control, Holden-Day, San Francisco,CA.

Buishand, T.A. (1982): "Some methods for testing the homogeneity of rainfall records", Journal of Hydrology, 58, 11-27.

Chang, T.J. (1988): "Stochastic forecast of water losses", Journal of Irrigation and Drainage Engineering,ASCE, 114(3), 547-558.

Chen, T.Y. (1976): "Evaporation and evapotranspiration in Hong Kong", Royal Observatory Technical
Note No:42, pp67.

Gupta, R.K. and Chauhan, H.S. (1986): "Stochastic model of issigation requirements", Journal of Irrigation and Drainage Engineering, ASCE, 112(1), 65-76.

Jayawardena, A.W.(1989): "Calibration of some empirical equations for evaporation and evapotranspiration in Hong Kong", Agricultural and Forest Meteorology, vol 47, pp 75-81.

Jayawardena, A.W. and Lai, F.Z. (1989): "Time series analysis of water quality data in Pearl River, China", Journal of 'Environmental Engineering, ASCE, vol 115, no 3, pp 590-607.

Kottegoda, N.T. (1980): Stochastic water resources technology, John Wiley, New York.

Ngan, P. and Russell, S.O. (1986): "Example of flow forecasting with Kalman filter", Journal of Hydraulic Engineering, ASCE, 112(9), 818-832.

Penman, H.L. (1948): "Natural evaporation from open water, bare soil and grass", Proc. Royal Soc. (London) Series A, 193, 120-146.

Ramage, C.S. (1959): "Evapotranspiration in Hong Kong, A second report", Pacific Science, XIII(1) 81-87.

Salas,J.D., Delleur, J.W., Yevjevich, V. and Lane, W. L. (1980):Applied modeling of hydrologic time series, Water resources publications, Littleton, Colorado.

Snedecor, G.W. and Cochran, W.G. (1967): Statistical methods. The Iowa State University Press, Iowa.

Srikanthan, R. and McMahon, T.A. (1982): "Simulation of annual and monthly rainfalls-A preliminary study at five Australian stations", Journal of Applied Meteorology, 21, 1472-1479.

Thornthwaite, C.W. (1948): "An approach towards a rational classification of climate", Geographical Review, 38, 55-94. 